\title{
PREFERRED ORIENTATIONS OF MICA BEARING ROCKS DESCRIBED BY TEXTURE COMPONENTS
}

\author{
K. HELMING ${ }^{1}$, D. SCHMIDT ${ }^{2}$ and K. ULLEMEYER ${ }^{3}$ \\ ${ }^{I}$ Department of Physical Metallurgy, TU Clausthal, Großer Bruch 23, \\ D-38678 Clausthal-Zellerfeld, Germany \\ ${ }^{2}$ Institute of Geology and Paleontology, TU Clausthal, Leibnizstr. 10, \\ D-38678 Clausthal-Zellerfeld, Germany \\ ${ }^{3}$ Joint Institute of Nuclear Research, Frank Laboratory for Neutron Physics, \\ 141980 Dubna, Moscow Region, Russia
}

(Received 26 July 1995)

\begin{abstract}
Up to now Texture investigations of phyllosilicates were restricted to pole density measurements of the (001) basal plane. Because of the tabular grain shape parallel to the basal plane an axial symmetry of the texture is assumed usually. This assumption was proved for four mica bearing samples by calculating the ODF from neutron diffraction data. Beside the mica-texture the textures of the other major fractions like quartz and feldspar were determined to detect correlation between them. The textures are explained by components. Each component is characterised by a preferred orientation or fibre axis, a corresponding spreading and an intensity $\mathrm{I}^{\mathrm{C}}$ describing the volume fraction of all crystallites belonging to the component. The presented component method can be applied to any crystal symmetry and to polyphase materials with overlapped pole figures.
\end{abstract}

KEY WORDS: Polyphase texture analysis of rocks, time-of-flight method, texture components.

\section{INTRODUCTION}

Earlier Quantitative Texture Analyses (QTA) of geological materials were mainly restricted to monophase samples or to single grain measurements on the U-stage (Schmid and Casey, 1986, Schmid et al., 1987, Kruhl, 1987, Mainprice and Munch 1993). QTA of polyphase materials was hampered by the high degree of overlapping Bragg reflections and the low symmetry of minerals, for which no algorithm to calculate the Orientation Distribution Function (ODF) was available. Meanwhile QTA is possible for all symmetries and polyphase materials (Helming and Eschner, 1991). Position-sensitive detector (Wenk et al., 1986, Will et al., 1989) and energy-dispersive measuring methods (Feldmann, 1989) allow the recording of more or less complete diffraction patterns, and large sample volumes can be investigated by means of neutron diffraction to obtain better counting statistics. Nevertheless, applications are rare although most rocks are of polyphase composition (Wenk and Pannetier, 1990, Helming, 1993, 1994, Siegesmund et al., 1994, Leiss et al., 1994). This paper deals with texture determinations of polyphase samples and focuses especially on the determination of mica textures. Based on the assumption, that phyllosilicates reorientated 
due to their tabular grain shape and preferred orientations of crystallographic faces other than the basal plane do not exist. First hints to the development of preferred orientations have been derived from the measurement of the anisotropy of magnetic susceptibility of mica bearing rocks. Texture determinations of this mineral group based on diffraction were restricted to pole density measurements of the (001) basal plane. The development of (001) preferred orientations and its relation to deformation is quite well understood (Weber, 1981, Sintubin, 1994), until recently no attempt to determine preferred orientations of other crystallographic directions has been reported. Applying $\mathrm{X}$-rays for (001) pole density measurements requires special corrections for progressive intensity loss due to the low penetration depth of X-rays, the very small scattering angle and the tabular grain shape of the crystallites (Ullemeyer and Weber, 1994). Pole density measurements by means of neutron diffraction allow the investigation of a much larger sample volume, due to the low absorption of neutrons, special correcting procedures as a consequence of anisotropic grain shape are not required. Nevertheless, the scattered intensities (and the contributions to overlapped Bragg reflections) of phyllosilicates are relatively low with respect to other minerals and large errors of texture determination be assumed.

To avoid the disadvantages mentioned above, determinations of pole figures were performed at the TOF-diffractometer NSHR at the pulsed reactor IBR-2 in Dubna, Russia (Feldmann, 1989). Due to the high resolution of that instrument peak overlappings may be reduced experimentally to a minimum, furthermore, the recording of complete diffraction patterns allows the definition of each desired d-range as an experimental pole figure. Four samples were selected to test the reliability of QTA of polyphase rocks: two muscovite-quartzites from the Taquaral Valley, Brazil (quartz and muscovite, Quade et al., 1994), and two granulites from the Moldanubian Zone, Austria (quartz, plagioclase and biotite, Ullemeyer, 1992).

\section{THE COMPONENT MODEL}

A direct numerical description of the ODF $\mathrm{f}(\mathrm{g})$ is quite expensive, because it requires three orientation parameters and one intensity value for a large number of discrete orientations $\mathrm{g}_{\mathrm{i}}$. The number of parameters decreases, if the orientations are given on a regular grid. Compared to this kind of ODF description, the required texture information for many applications is much more compact, but it may be difficult to find out the parameters, which are really important for ODF approximation. Another disadvantage is the necessary interpolation of ODF-values, which do not match the given grid points. In that case, the approximation of the ODF by simple functions, which can be handled easily on the computer, should be used. Most propagation the series expansion with generalized spherical harmonics (Bunge, 1965) has reached:

$$
\mathrm{f}(\mathrm{g})=\sum_{1} \sum_{\mathrm{m}, \mathrm{n}} \mathrm{C}_{1}^{\mathrm{mn}} \mathrm{T}_{1}^{\mathrm{mn}}(\mathrm{g}) \text {. }
$$

They form an orthogonal system of basic functions. Besides this numerical advantage mean values of anisotropic properties can be efficiently calculated by means of the corresponding $\mathrm{C}$-coefficients. The basic functions $\mathrm{T}$ are periodic in the whole $\mathrm{G}$-space (period length $2 \pi / 1$ ), so this type of approximation is suitable to characterize the periodical behaviour of the ODF. If the main features of the texture can be described by a few preferred orientations, the number of $\mathrm{C}$-coefficients can be much larger as 
the number of parameters, which is really required for texture description. In such cases the ODF-approximation by means of texture components

$$
\begin{aligned}
& \mathrm{f}(\mathrm{g})=\mathrm{F}+\sum_{\mathrm{c}=1}^{\mathrm{C}} \mathrm{I}^{\mathrm{c}} \mathrm{f}^{\mathrm{c}}(\mathrm{g}) \\
& \text { with } \mathrm{F}+\sum_{\mathrm{c}=1}^{\mathrm{C}} \mathrm{I}^{\mathrm{c}}=1 \text { and } \oiiint_{\mathrm{G}} \mathrm{f}^{\mathrm{c}}(\mathrm{g}) \mathrm{dg}=1
\end{aligned}
$$

should be preferred (Wassermann, 1939; Bunge, 1969; Matthies et al., 1989-1992). A component is described by a model function $\mathrm{f}^{\mathrm{c}}(\mathrm{g})$, which is locally restricted in the G-space, and an intensity $I^{c}$, which describes the volume fraction of all crystallites belonging to the component $\mathrm{c}$. The quantity $\mathrm{F}$ gives the volume fraction of the crystallites, which are randomly oriented in the sample. It may be understood as the intensity of the only global (not restricted in the G-space) component used in the model, which is given by $\mathrm{f}^{0}(\mathrm{~g})=1$ for each $\mathrm{g} \in \mathrm{G}$.

$f^{c}(g)$ has a maximum at a preferred orientation $g^{c}$ and decreases with increasing orientation distance $\tilde{\omega}^{\mathrm{c}}$, which is defined by the rotation angle

$$
\cos \frac{\tilde{\omega}^{\mathrm{c}}}{2}=\cos \frac{\omega^{\mathrm{c}}}{2} \cos \frac{\omega}{2}+\mathbf{n}^{\mathrm{c}} \cdot \mathbf{n} \sin \frac{\omega^{\mathrm{f}}}{2} \sin \frac{\omega}{2}
$$

of the orientation difference $\tilde{\mathrm{g}}^{\mathrm{c}}=\left[\tilde{\omega}^{\mathrm{c}}, \tilde{\mathbf{n}}^{\mathrm{c}}\right]=\mathrm{g}^{\mathrm{c}} \mathrm{g}^{-1}$ between $\mathrm{g}^{\mathrm{c}}=\left[\omega^{\mathrm{c}}, \mathbf{n}^{\mathrm{c}}\right]$ and $\mathrm{g}=[\omega$, $\mathbf{n}]$. If the intensity decrease does not depend on the rotation axis $\tilde{\mathbf{n}}^{\mathrm{c}}$, the component is called isotropic. An anisotropic component is characterized by a fibre axis $\mathbf{y}^{\mathrm{c}}$ given in the sample coordinate system $\mathrm{K}_{\mathrm{A}}$. The corresponding model function $\mathrm{f}^{\mathrm{c}}(\mathrm{g})$ remains unchanged rotating around $\mathbf{y}^{c}$. Its maxima form a great circle in the orientation space given by $\overline{\mathrm{g}}^{\mathrm{c}}=\left[\omega, \pm \mathrm{y}^{\mathrm{c}}\right] \mathrm{g}^{\mathrm{c}}$ with $0 \leq \omega \leq \pi$, which includes the preferred orientation $\mathrm{g}^{\mathrm{c}}$. The distribution depends only on the angle between the directions $\mathrm{g} \mathbf{y}^{\mathrm{c}}$ and $\mathrm{g}^{\mathrm{c}} \mathbf{y}^{\mathrm{c}}$.

With a Gaussian standard distribution for the isotropic component (Matthies et al., 1989-1992) we have

$$
\begin{aligned}
& \mathrm{f}^{\mathrm{c}}(\mathrm{g})=\mathrm{N}^{\mathrm{c}} \mathrm{e}^{\mathrm{S}^{\mathrm{c}} \cos \widetilde{\sigma}^{\mathrm{c}}} \\
& \text { with } \quad \mathrm{S}^{\mathrm{c}}=\frac{\ln 2}{1-\cos \left(\mathrm{b}^{\mathrm{c}} / 2\right)} \quad \text { and } \quad \mathrm{N}^{\mathrm{c}}=\frac{1}{\mathrm{I}_{0}\left(\mathrm{~S}^{\mathrm{c}}\right)-\mathrm{I}_{1}\left(\mathrm{~S}^{\mathrm{c}}\right)}
\end{aligned}
$$

where $I_{1}(x)$ are generalized Bessel functions and $b^{c}$ is the FWHM of the distribution. The corresponding pole figures are given by analytical expressions

$$
\mathrm{P}_{\mathrm{h}}^{\mathrm{c}}(\mathbf{y})=\mathrm{N}^{\mathrm{c}} \mathrm{e}^{\mathrm{S}^{\mathrm{c}} \sin (\vartheta / 2)} \mathrm{I}_{0}\left(\mathrm{~S}^{\mathrm{c}} \cos (\vartheta / 2)\right) \text { with } \cos \vartheta=\mathbf{h g}^{\mathrm{c}} \mathbf{y} .
$$

Fibre components are described by

$$
\begin{aligned}
& f^{c}(g)=N_{f}^{c} e^{S_{f}^{c}\left(g y^{c} \cdot g^{c} y^{c}\right)} \\
& \text { with } \quad S_{f}^{c}=\frac{\ln 2}{1-\cos \left(b_{f}^{c} / 2\right)} \quad \text { and } \quad N_{f}^{c}=\frac{S_{f}^{c}}{\sinh \left(S_{f}^{c}\right)}
\end{aligned}
$$

and 


$$
\begin{aligned}
& \mathrm{P}_{\mathrm{h}}^{\mathrm{c}}(\mathbf{y})=\mathrm{N}_{\mathrm{f}}^{\mathrm{c}} \mathrm{e}^{\mathrm{S}_{\mathrm{f}}^{\mathrm{c}} \cos \left(\vartheta_{\mathrm{h}}\right) \cos \left(\vartheta_{\mathrm{y}}\right)} \mathrm{I}_{0}\left(\mathrm{~S}_{\mathrm{f}}^{\mathrm{c}} \sin \left(\vartheta_{\mathrm{h}}\right) \sin \left(\vartheta_{\mathrm{y}}\right)\right) \\
& \text { with } \quad \cos \vartheta_{\mathrm{h}}=\mathbf{h} \cdot \mathrm{g}^{\mathrm{c}} \mathbf{y}^{\mathrm{c}}, \cos \vartheta_{\mathrm{y}}=\mathbf{y} \cdot \mathbf{y}^{\mathrm{c}}
\end{aligned}
$$

In contrast to the series expansion with generalized harmonics (Bunge 1965) the component descriptions is not unique especially for weak textures. So the description of a random distribution with $\mathrm{f}(\mathrm{g})=1$ for each $\mathrm{g}$ may be given by $\mathrm{F}=1$ or a finite number of components, which are regularly arranged in the G-space. On the other hand, the component description allows the controlled restriction of texture information. As shown below this can be necessary, if the quality or quantity of measured data does not allow precise calculation of the ODF. Taking into account only a small number of components, an estimation of the ODF may be possible at least. Searching for important symmetries or parameter of texture forming processes restrictions on special types of components may be useful. The main purpose of this paper is to investigate the coupling between the texture of mica and its axial morphology. If this coupling is dominant, we should expect textures which can be described by fibre components.

\section{DETERMINATION OF THE COMPONENT PARAMETERS FROM DIFFRACTION DATA}

PFs which are measured in a diffraction experiment can be understood as twodimensional projections of the three-dimensional ODF

$$
\tilde{\mathbf{P}}_{\mathbf{h}}(\mathbf{y})=\frac{1}{2}\left[\mathrm{P}_{\mathbf{h}}(\mathbf{y})+\mathrm{P}_{-\mathbf{h}}(\mathbf{y})\right]=\oint_{ \pm \mathbf{n} \| \mathbf{y}} \mathrm{f}\left(\mathrm{g}_{\varphi}\right) \mathrm{d} \varphi .
$$

$\mathrm{g}_{\varphi}$ describes all orientations with its lattice plane normal $\mathbf{h}$ parallel (or antiparallel) to the scattering vector $\mathbf{y}$, which is named sample direction and given with respect to the sample coordinate system. Because of Friedel's law PFs are affected by an additional inversion center allowing only the measurement of reduced $\operatorname{PFs} \tilde{\mathrm{P}}_{\mathbf{h}}(\mathbf{y})$. Especially for low crystal symmetries and multiphase systems Bragg-reflections of lattice planes may have the same or similar lattice distances

$$
\mathrm{d}_{(\mathrm{hkl})}^{\mathrm{p}}=\mathrm{d}_{\left(\mathrm{h}^{\prime} \mathrm{k}^{\prime} \mathrm{l}^{\prime}\right)}^{\mathrm{p}^{\prime}}, \quad \mathrm{d}_{(\mathrm{hkl})}^{\mathrm{p}} \approx \mathrm{d}_{\left(\mathrm{h}^{\prime} \mathrm{k}^{\prime} \mathrm{l}^{\prime}\right)}^{\mathrm{p}^{\prime}}
$$

causing total or partial coincidence. The diffraction pole figures then read

$$
\tilde{\mathrm{D}}_{\mathrm{d}}(\mathbf{y})=\mathrm{N}_{\mathrm{d}} \sum_{\mathrm{p}, \mathrm{i}} \mathrm{q}_{\mathrm{id}}^{\mathrm{p}} \tilde{\mathbf{P}}_{\mathbf{h}_{\mathbf{i}}}^{\mathrm{p}}(\mathbf{y}) \quad \text { with } \quad \sum_{\mathrm{p}, \mathrm{i}} \mathrm{q}_{\mathrm{id}}^{\mathrm{p}}=1
$$

where $\mathrm{p}$ and $\mathrm{i}$ mark the phases and the lattice planes, which contribute to a superposed PF $\tilde{D}_{d}(y)$. The values $N_{d}$ and $q_{\text {id }}^{p}$ depend on structure, phase fractions and absorption in a complex manner (Bunge et al., 1989), in the general case they must be treated as unknown parameters.

Now for each phase $p$ a component description of the corresponding ODF $\mathrm{f}^{\mathrm{p}}(\mathrm{g})$ is searched, trying to find the best fit of the experimental data $\tilde{D}_{\mathrm{d}}\left(\mathrm{y}_{\mathrm{r}}\right)$ with the pole figures $\tilde{D}_{d}^{M}\left(\mathbf{y}_{\mathrm{r}}\right)$ recalculated from the component model for all measured sample directions $\mathbf{y}_{\mathrm{r}}$. The component parameters $I^{\mathrm{pc}}, \mathrm{g}^{\mathrm{pc}}, \mathbf{y}^{\mathrm{pc}}, \mathrm{b}^{\mathrm{pc}}$ and $\mathrm{b}_{\mathrm{f}}^{\mathrm{pc}}$ and the values $\mathrm{N}_{\mathrm{d}}$ and $\mathrm{q}_{\mathrm{id}}^{\mathrm{p}}$ can be determined solving the least squares problem 


$$
\sum_{\mathrm{i}, \mathrm{r}} \varpi_{\mathrm{ir}}\left[\tilde{\mathrm{D}}_{\mathrm{d}}\left(\mathbf{y}_{\mathrm{r}}\right) / \mathrm{N}_{\mathrm{d}}-\sum_{\mathrm{p}, \mathrm{i}} \mathrm{q}_{\mathrm{id}}^{\mathrm{p}} \sum_{\mathrm{c}} \mathbf{I}^{\mathrm{pc}} \tilde{\mathrm{P}}_{\mathbf{h}_{\mathrm{i}}^{\mathrm{p}}}^{\mathrm{p}}\left(\mathrm{g}^{\mathrm{pc}}, \mathbf{y}^{\mathrm{pc}}, \mathrm{b}^{\mathrm{pc}}, \mathrm{b}_{\mathrm{f}}^{\mathrm{pc}}, \mathbf{y}_{\mathrm{r}}\right)\right]^{2} \Rightarrow \text { Min. }
$$

To determine the parameters $g^{p c}, y^{p c}, b^{p c}$ and $b_{f}^{p c}$ by a nonlinear algorithm, first estimates are necessary, which may be obtained manually from the graphical representation of the difference pole figures

$$
\tilde{D}_{d}^{-}\left(\mathbf{y}_{\mathrm{r}}\right)=\frac{\tilde{D}_{d}\left(\mathbf{y}_{\mathrm{r}}\right)-\tilde{D}_{d}^{M}\left(\mathbf{y}_{\mathrm{r}}\right)}{N_{d}}
$$

on a PC-Monitor.

This procedure is explained in more detail in Helming and Eschner (1991) and Helming et al. (1994). The calculation of the model pole figures $\mathrm{P}_{\mathrm{h}_{\mathrm{p}}^{\mathrm{p}}}^{\mathrm{p}}$ follows from (5), (7) and (8).

\section{RESULTS}

The TOF diffraction pattern of sample STG (Figure 1) shows the high degree of overlapping of Bragg reflections of a polyphase sample containing low symmetrical constituents. The chosen sample consists of quartz $(\approx 40 \%)$, plagioclase $(\approx 35 \%)$, biotite $(\approx 7 \%)$, K-feldspar $(\approx 10 \%)$ and accessory minerals. At small d-values $(d<2.7 \AA)$ the number of reflections and consequently the number of partial and complete overlapping increases rapidly. In most cases an experimental PF encompasses peaks of two or more phases (Table 1), PFs consisting of only one lattice plane or reflections of only one phase are rare.

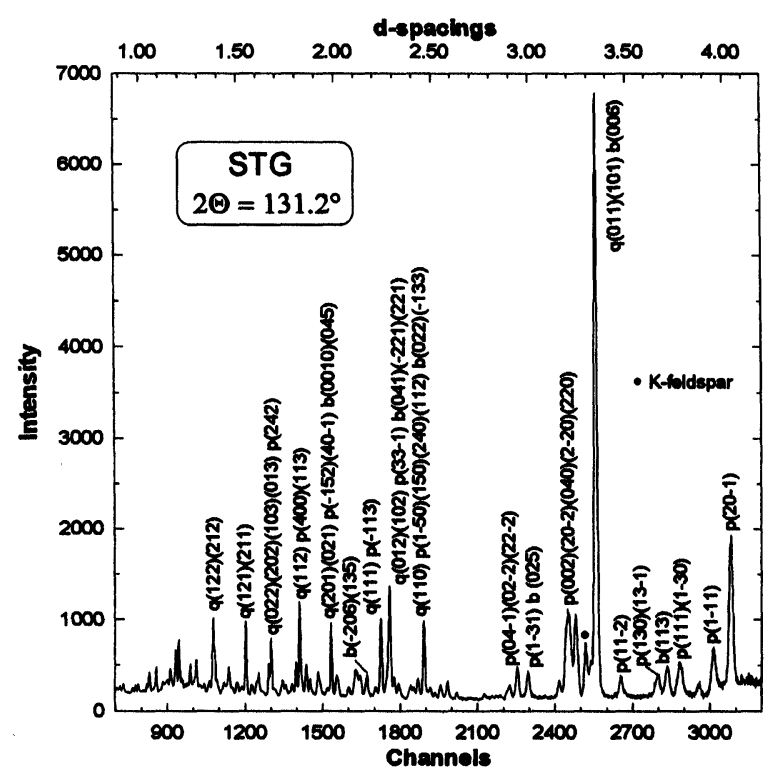

Figure 1 TOF diffraction pattern of sample STG. It contains quartz (q), plagioclase (p), biotite (b), $\mathrm{K}$-feldspar and accessory minerals. Intensities are normalized with respect to the energy distribution of the reactor spectrum and given in arbitrary units, channel width at the time scale (channels) is $64 \mu$ s. 
Table 1 PF-Normalization $\mathrm{N}_{\mathrm{d}}$ (norm), RP- values and intensity contributions $\mathrm{q}_{\mathrm{id}}^{\mathrm{p}}$ of overlapped Bragg reflections (hkl) of sample STG (q: quartz, p: plagioclase, b: biotite). For discussion see text.

\begin{tabular}{|c|c|c|c|c|c|c|c|}
\hline \multirow{2}{*}{$\begin{array}{r}\text { norm } \\
2.5\end{array}$} & \multirow{2}{*}{$\begin{array}{r}R P O \\
18\end{array}$} & & & \multicolumn{2}{|c|}{$\begin{array}{c}h k l q_{i d}^{p} \\
\quad p\end{array}$} & \multicolumn{2}{|l|}{$b$} \\
\hline & & & & $\left(\begin{array}{ll}1-1 & 1\end{array}\right)$ & 100.0 & & \\
\hline 12.5 & 13 & & & $\left(\begin{array}{lll}\left(\begin{array}{lll}1 & 1 & 1\end{array}\right) \\
\left(\begin{array}{lll}1 & -3 & 0\end{array}\right)\end{array}\right.$ & $\begin{array}{l}51.1 \\
48.9\end{array}$ & & \\
\hline 3.8 & 16 & & & $\left(\begin{array}{ll}2 & 2-1\end{array}\right)$ & 100.0 & & \\
\hline 85.3 & 7 & 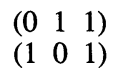 & $\begin{array}{l}74.4 \\
23.0\end{array}$ & & & $\left(\begin{array}{lll}0 & 0 & 6\end{array}\right)$ & 2.6 \\
\hline 53.6 & 12 & & & 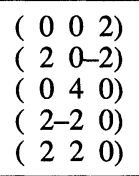 & $\begin{array}{r}30.0 \\
26.1 \\
24.1 \\
9.9 \\
9.9\end{array}$ & & \\
\hline 6.6 & 11 & & & $\left(\begin{array}{ll}1-3 & 1\end{array}\right)$ & 76.3 & $\left(\begin{array}{lll}0 & 2 & 5\end{array}\right)$ & 23.7 \\
\hline 10.8 & 11 & & & 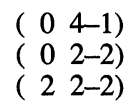 & $\begin{array}{l}45.6 \\
29.1 \\
25.3\end{array}$ & & \\
\hline 8.3 & 16 & & & $\left(\begin{array}{ll}2 & 4-1\end{array}\right)$ & 98.2 & $\left(\begin{array}{lll}1 & 3 & 2\end{array}\right)$ & 1.8 \\
\hline 46.7 & 9 & $\left(\begin{array}{lll}1 & 1 & 0\end{array}\right)$ & 59.8 & $\begin{array}{l}\left(\begin{array}{lll}1 & -5 & 0\end{array}\right) \\
\left(\begin{array}{lll}1 & 5 & 0\end{array}\right) \\
\left(\begin{array}{lll}2 & 4 & 0\end{array}\right) \\
\left(\begin{array}{lll}1 & 1 & 2\end{array}\right)\end{array}$ & $\begin{array}{l}7.9 \\
6.7 \\
6.1 \\
6.1\end{array}$ & 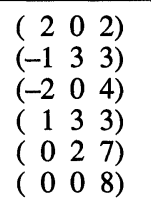 & $\begin{array}{l}5.5 \\
2.7 \\
1.8 \\
1.7 \\
0.9 \\
0.8\end{array}$ \\
\hline 44.3 & 8 & $\begin{array}{l}\left(\begin{array}{lll}0 & 1 & 2\end{array}\right) \\
\left(\begin{array}{lll}1 & 0 & 2\end{array}\right)\end{array}$ & $\begin{array}{r}76.5 \\
8.7\end{array}$ & ( $\left.\begin{array}{ll}3 & 3\end{array}-1\right)$ & 10.2 & 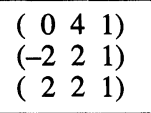 & $\begin{array}{l}2.3 \\
1.2 \\
1.1\end{array}$ \\
\hline 35.7 & 7 & $\left(\begin{array}{lll}1 & 1 & 1\end{array}\right)$ & 87.2 & $\left(\begin{array}{lll}-1 & 1 & 3\end{array}\right)$ & 12.8 & & \\
\hline 20.4 & 13 & & & & & $\begin{array}{rlll}\left(\begin{array}{lll}-2 & 0 & 6\end{array}\right) \\
\left(\begin{array}{rll}1 & 3 & 5\end{array}\right) \\
\end{array}$ & $\begin{array}{l}50.5 \\
49.5 \\
\end{array}$ \\
\hline 39.5 & 9 & & & 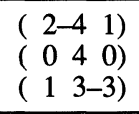 & $\begin{array}{l}60.0 \\
22.7 \\
17.3 \\
\end{array}$ & & \\
\hline 58.4 & 9 & $\begin{array}{l}\left(\begin{array}{lll}2 & 0 & 1\end{array}\right) \\
\left(\begin{array}{lll}0 & 2 & 1\end{array}\right)\end{array}$ & $\begin{array}{r}76.8 \\
4.5 \\
\end{array}$ & 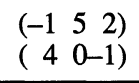 & $\begin{array}{l}7.9 \\
5.1 \\
\end{array}$ & 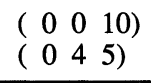 & $\begin{array}{l}4.3 \\
1.4 \\
\end{array}$ \\
\hline 21.7 & 13 & & & $\left(\begin{array}{lll}-4 & 2 & 2\end{array}\right)$ & 75.0 & 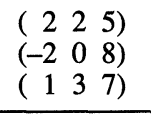 & $\begin{array}{l}9.4 \\
8.3 \\
7.3 \\
\end{array}$ \\
\hline 21.3 & 12 & & & $\left(\begin{array}{lll}1 & 1 & 1\end{array}\right)$ & 84.6 & $\left(\begin{array}{lll}-2 & 2 & 7\end{array}\right)$ & 15.4 \\
\hline 27.9 & 14 & & & $\left(\begin{array}{ll}2 & 2-1\end{array}\right)$ & 100.0 & & \\
\hline 47.9 & 12 & $\left(\begin{array}{lll}2 & 1 & 0\end{array}\right)$ & 100.0 & & & & \\
\hline
\end{tabular}


The results of component deconvolution of the four investigated samples are summarized in the Tables 2 and 3. A various number of peak- and fibre-components was determined. The most interesting features are be discussed below:

- the mica textures are characterized not only by fibre components with its axes parallel to the basal plane normal, significant peak components were also found (P17316, P16815). The sharpness of both textures in these samples guarantees that the calculated preferred orientations and the corresponding halfwidths are no artifacts.

Table 2 Results of QTA (Taquaral samples). Intensity $I^{c}$ and halfwidth $b^{c} / b_{f}^{c}$ of the components are given. Fibre components are indicated by bold letters. To give some impression on the quality of texture reproduction, RP0 of the texture and the range of RPO of the PFs (in brackets) are given.

\begin{tabular}{|c|c|c|c|c|c|c|c|c|}
\hline & \multicolumn{4}{|c|}{ P17316 RPO: 19 (14-27) } & \multicolumn{4}{|c|}{ P16815 RPO: 12 (9-13) } \\
\hline & $q$ & & $m$ & & $q$ & & $m$ & \\
\hline & $I^{c}$ & $b^{c} / b_{f}^{c}$ & $I^{c}$ & $b^{c} / b_{f}^{c}$ & $I^{c}$ & $b^{c} / b_{f}^{c}$ & $I^{c}$ & $b^{c} / b_{f}^{c}$ \\
\hline $\mathbf{F}$ & 27.7 & & 50.9 & & 77.1 & & 74.9 & \\
\hline $\begin{array}{l}1 \\
2 \\
3 \\
4 \\
5 \\
6 \\
7 \\
8 \\
9 \\
10 \\
11 \\
\end{array}$ & $\begin{array}{r}21.9 \\
15.1 \\
9.2 \\
6.2 \\
4.4 \\
4.0 \\
3.3 \\
3.3 \\
2.4 \\
1.6 \\
0.9\end{array}$ & $\begin{array}{l}26.1 \\
26.5 \\
21.9 \\
23.3 \\
22.3 \\
17.0 \\
18.1 \\
18.6 \\
19.6 \\
16.0 \\
19.5\end{array}$ & $\begin{array}{r}13.4 \\
12.1 \\
6.8 \\
6.5 \\
6.2 \\
3.4 \\
0.7\end{array}$ & $\begin{array}{l}34.3 \\
31.0 \\
28.3 \\
24.9 \\
32.0 \\
22.4 \\
19.8\end{array}$ & $\begin{array}{l}8.7 \\
7.1 \\
3.6 \\
3.5\end{array}$ & $\begin{array}{l}39.9 \\
28.9 \\
24.3 \\
32.1\end{array}$ & $\begin{array}{l}7.0 \\
6.4 \\
3.1 \\
2.8 \\
1.9 \\
1.7 \\
1.2 \\
1.0\end{array}$ & $\begin{array}{r}8.7 \\
26.5 \\
23.6 \\
21.4 \\
15.8 \\
18.9 \\
12.5 \\
10.6\end{array}$ \\
\hline
\end{tabular}

Table 3 Results of QTA of the granulite samples. For details see table 2.

\begin{tabular}{|c|c|c|c|c|c|c|c|c|c|c|c|c|}
\hline & \multicolumn{2}{|c|}{ STG } & $R P 0: 12$ & \multicolumn{2}{|c|}{$(7-18)$} & & \multicolumn{2}{|c|}{$M G$} & RPO: 11 & \multicolumn{2}{|c|}{$(7-16)$} & \\
\hline & $q$ & & $\boldsymbol{b}$ & & $p$ & & $q$ & & $\boldsymbol{b}$ & & $p$ & \\
\hline & $I^{c}$ & $b^{c} / b_{f}^{c}$ & $I^{c}$ & $b^{c} / b_{f}^{c}$ & $I^{c}$ & $b^{c} / b_{f}^{c}$ & $I^{c}$ & $b^{c} / b_{f}^{c}$ & $I^{c}$ & $b^{c} / b_{f}^{c}$ & $I^{c}$ & $b^{c} / b_{f}^{c}$ \\
\hline $\mathrm{F}$ & 65.4 & & 94.2 & & 78.4 & & 83.4 & & 93.0 & & 75.0 & \\
\hline 1 & 12.1 & 32.6 & 4.4 & 10.5 & 5.5 & 56.5 & 11.4 & 21.6 & 5.7 & 11.2 & 20.4 & 40.1 \\
\hline 2 & 7.0 & 34.6 & 1.4 & 9.5 & 3.1 & 41.9 & 1.7 & 27.5 & 0.7 & 20.4 & 1.4 & 29.1 \\
\hline 3 & 2.6 & 32.6 & & & 3.0 & 42.3 & 1.3 & 22.9 & 0.6 & 13.7 & 1.3 & 31.2 \\
\hline 4 & 2.6 & 32.9 & & & 2.5 & 40.7 & 0.8 & 20.1 & & & 1.2 & 27.1 \\
\hline 5 & 2.4 & 33.0 & & & 1.5 & 28.0 & 0.8 & 19.7 & & & 0.7 & 19.3 \\
\hline 6 & 2.0 & 25.2 & & & 1.4 & 32.9 & 0.6 & 20.6 & & & & \\
\hline 7 & 2.0 & 29.3 & & & 1.1 & 25.1 & & & & & & \\
\hline 8 & 1.5 & 23.9 & & & 0.9 & 20.8 & & & & & & \\
\hline 9 & 1.1 & 21.1 & & & 0.9 & 28.6 & & & & & & \\
\hline 10 & 0.7 & 21.0 & & & 0.9 & 21.9 & & & & & & \\
\hline 11 & 0.6 & 25.1 & & & 0.8 & 23.0 & & & & & & \\
\hline
\end{tabular}


- the random part $\mathrm{F}$ of the textures is quite large. It ranges between $27.7 \%$ and $77.1 \%$ for the two-phase samples and between $65.4 \%$ and $94.2 \%$ for the three-phase samples. But because of the high degree of superposition of the measured pole figures, $\mathrm{F}$ and the component intensities $\mathrm{I}^{\mathrm{c}}$ must be considered only as estimates. The quality of texture reproduction is described by the global error parameter RP0 (Matthies et al., 1988). RP0- values of the textures range between 11\% and 19\%, the spread for single PFs is sometimes large (Tables 2 and 3, Figure 2).

In the Figures 3, 4 and 5 recalculated pole figures of some lattice directions are presented, which are of interest for the kinematic interpretation. The predominant features are:

- in agreement with the dominance of fibre components, the mica PFs are characterized by axial symmetric intensity distributions, which are more or less modified by the peak components.

- in sample P17316 only peak components could be found. In contrast to the other samples the pole density maximum of the (001) basal plane PF deviates from the foliation pole by about $30^{\circ}$ and the (100) and (010) directions also display preferred orientations.

- the recalculated quartz (0001) and $11 \overline{2} 0$ PFs correspond to commonly observed orientation patterns. They are generally described exclusively by peak components, in the case of sample MG the texture is dominated by a fibre component with its axis parallel to the (011) normal.

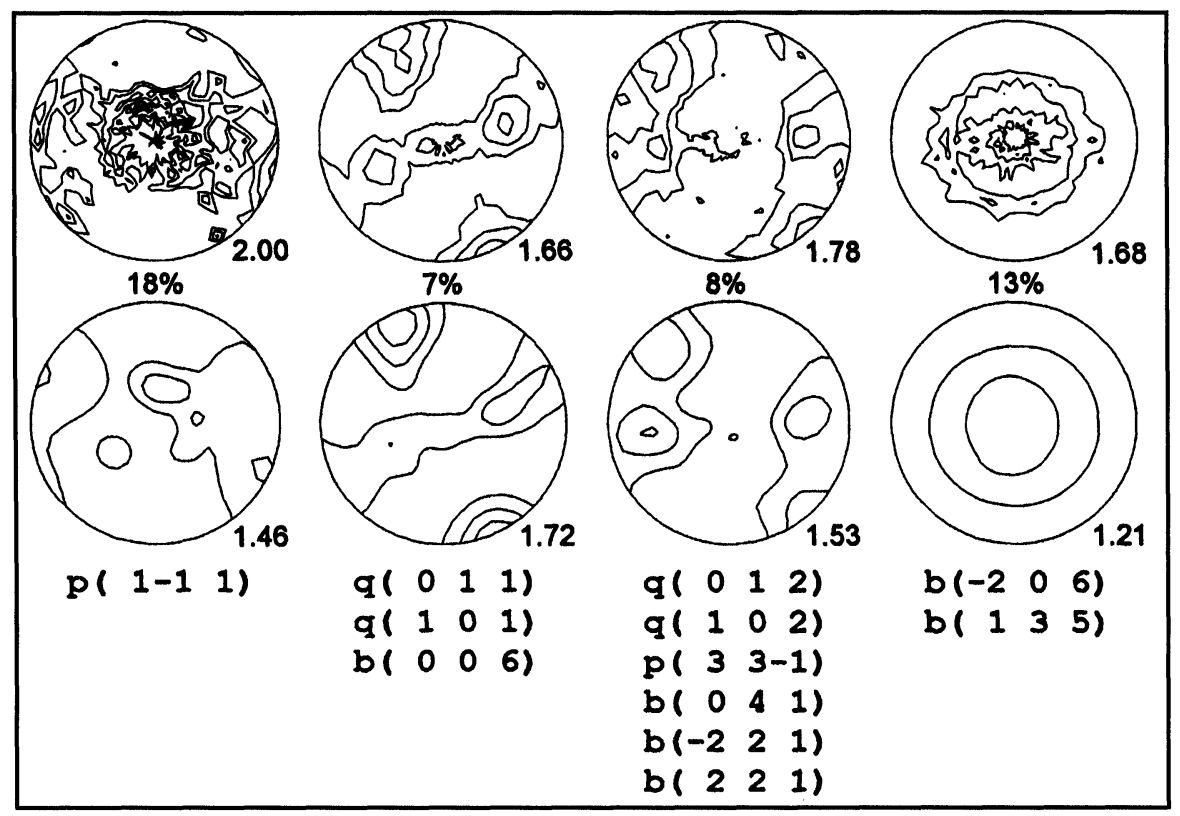

Figure 2 Some selected experimental and recalculated PFs of sample STG. Projection plane is onto the foliation, the lattice planes comprised in the PFs and RPO- values are indicated. The maximum intensity is displayed at the bottom right of the corresponding PFs, contouring begins at one time random. 

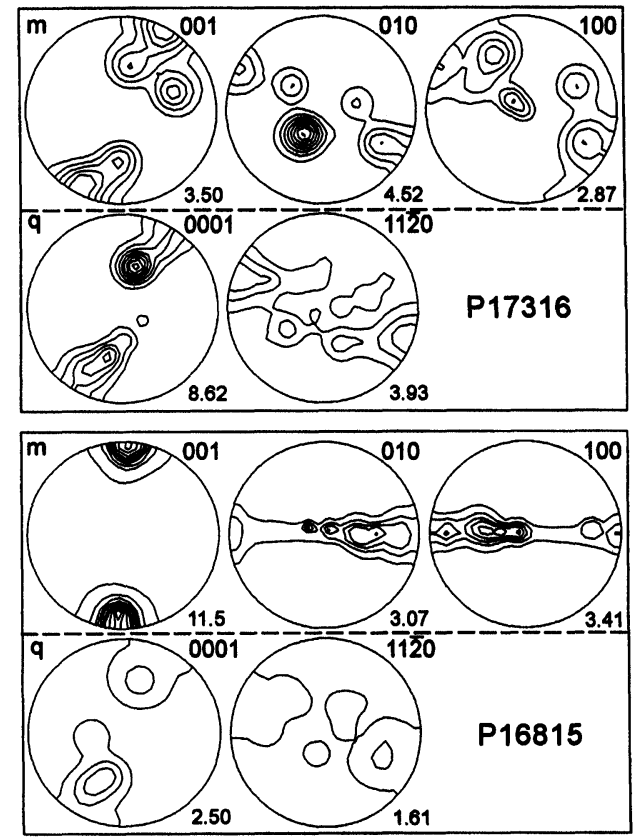

Figure 3 Recalculated PFs (q: quartz, m: muscovite) of the Taquaral samples. The projection plane is perpendicular to the foliation and parallel to the macroscopic lineation. For further explanations see Figure 2.

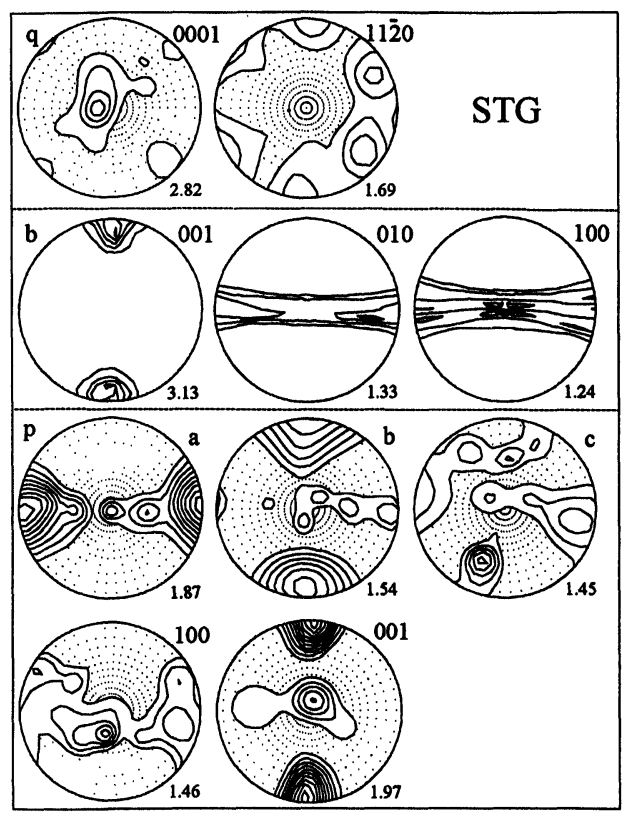

Figure 4 Recalculated PFs (q: quartz, b: biotite, p: plagioclase) of sample STG. For further explanations see Figure 3. 


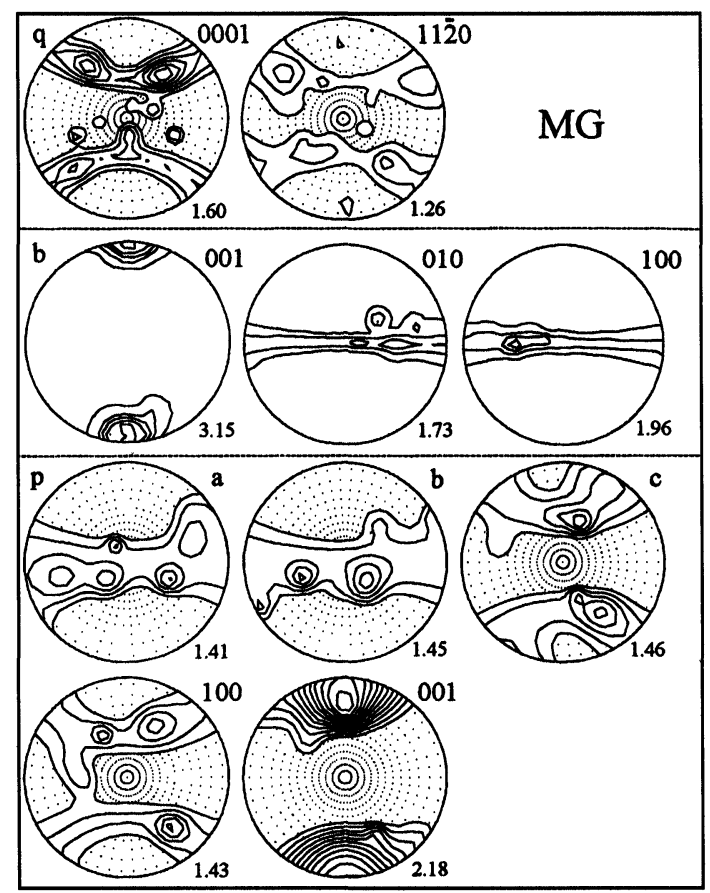

Figure 5 Recalculated PFs (q: quartz, b: biotite, p: plagioclase) of sample MG. For further explanations see Figure 3.

- the recalculated plagioclase PFs are either described by peak components (sample STG) or by one dominant fibre component with its axis close to the (001) normal and a number of small peak components (sample MG).

\section{DISCUSSION}

The high degree of superposed Bragg reflections has consequences for the quality of texture reproduction of the rock constituents. An important influence may be inferred from the relative intensity contribution $\mathrm{q}_{\text {id }}^{\mathrm{p}}$ of a lattice plane to a measured $\mathrm{PF}$, which depends on the scattering behaviour and the volume fraction of the mineral phase in the sample. Quartz generally scatters much more than plagioclase and mica minerals. All superposed PFs with contributions of quartz are dominated by this mineral. Small volume fractions (e.g. mica: typically $5-15 \%$ in the considered kind of rock) additionally reduce the intensity contributions to an experimental PF. The overlapped PF q (011) + q (101) + b (006) of sample STG (quartz: 40\%, biotite: $7 \%$ ) may serve as an example. The intensity contribution $\mathrm{q}_{\mathrm{id}}^{\text {biotite }}$ is $2.6 \%$ (Table 1), i.e. biotite causes only a minor modification of the $\mathrm{q}(011)+\mathrm{q}(101)$ intensity contribution, although a strong preferred orientation of the biotite (006) basal plane is confirmed by independent X-ray measurements (Ullemeyer 1992). In the corresponding PFs of Figure 2 this intensity maximum is located in the centre. It is assumed, that intensity 
contributions to such a small degree are close to the error magnitude to be expected, and therefore the efficiency of that PF for the determination of the biotite texture is minimal.

\section{CONCLUSIONS}

Because of the morphology of phyllosilicate grains, ODF calculations always require diffraction measurements with neutrons possessing a high penetration depth. However in quartzite it is impossible to find separate mica reflections which do not belong to the basal plane. Therefore the error magnitude of the quantities $q, N, I, F$, calculated by the component method, may be considerable. But if, like in our cases, the investigated textures are not too weak, the method allows an accurate determination of preferred orientations and corresponding halfwidths. Beside the measurement of the anisotropy of magnetic susceptibility this gives another, more precise tool to investigate the behaviour of mica during texture-forming processes. From this point of view our results show uniquely that mica-textures are much more complicated as assumed up to now and they are not axial symmetrical in each case. Texture modifying processes in a mica bearing rock may consequently depend on both, the tabled shape of the grains (axial symmetrical) and the crystal lattice (monoclinic). To describe the interface between these extreme cases rotational, elliptical components (Eschner, 1993, Helming, 1994) will be used in future.

The amount of texture information, that can be determined with the component method, is dependend on the quantity and quality of the measured data. Hence, like shown in the presented multi-phase examples, the determination of the most important texture information is possible starting from $\approx 20$ pole figures measured by neutron diffraction.

\section{Acknowledgements}

We are grateful to all colleagues from Clausthal, Dubna and Göttingen who helped us to prepare the samples and the pole figure data. The permission of Prof. Quade to use the neutron diffraction data of the Taquaral samples is also gratefully acknowledged. This research project was supported by the Bundesministerium für Bildung, Wissenschaft, Forschung and Technologie.

\section{References}

Bunge, H. J. (1965). Zur Darstellung allgemeiner Texturen. Z. Metallkunde, 56, 872-874.

Bunge, H. J. (1969). Mathematische Methoden der Texturanalyse. Berlin: Akademie-Verlag.

Bunge, H. J., Dahms, M. and Brokmeier, H. G. (1989). The determination of the integrated intensities from polycrystalline samples with preferred orientations. Cryst. Rev., 2, 67-88.

Feldmann, K. (1989). Texture Investigations by Neutron Time-of-Flight Diffraction. Textures and Microstructures, 10, 309-323.

Eschner, T. (1993). Texture analysis by means of model functions. Textures and Microstructures, 21, 139-146.

Helming, K. and Eschner, T. (1991). A new approach to texture analysis of multiphase materials using a texture component model. Cryst. Res. Technol., 25, K203-K208.

Helming, K. (1993). Geometric approximation method for texture analysis of rocks. Physics of the Solid Earth, engl. Übersetzung: Vol. 29, No. 6, (1994), 523-532; russ. Ausgabe (1993), 73-82.

Helming, K. (1994a). Some applications of the texture component model. In: H. J. Bunge (Hrsg.): Proc. Tenth Int. Conf. Text. Mat. (ICOTOM 10). Clausthal, Materials Science Forum, 157-162, 363-368. 
Helming, K., Wenk, H.-R., Choi, C. S. and Schafer, W. (1994). Description of quartz textures by components. Examples from metamorphic rocks. In Textures of Geological Materials, edited by $\mathrm{H}$. J. Bunge, S. Siegesmund, W. Skrotzki and K. Weber, pp. 303-326. Oberursel: DGM Informationasgesellschaft-Verlag.

Leiss, B., Helming, K., Siegesmund, S. and Weber, K. (1994). Quantitative Texture Analysis of Naturally Deformed Polyphase Dolomite Marbles and its Kinematic Significance. Materials Science Forum 157-162, 789-794.

Mainprice, D. and Munch, P. (1993). Quantitative texture analysis of an anorthosite - application to thermal expansion, Young's modulus and thermal stresses. Textures and Microstructures, 21, 79-92.

Matthies, S., Vinel, G. W. and Helming, K. (1987-1990). Standard Distributions in Texture Analysis I-III. Berlin: Akademie-Verlag.

Matthies, S., Wenk, H.-R. and Vinel, G. W. (1988). Some basic concepts of texture analysis and comparison of three methods to calculate orientation distributions from pole figures. J. Appl. Cryst., 21, 285-304.

Quade, H., Reinert, T. and Schmidt, D. (1994). Diamagnetic Anisotropy of Precambrian Quartzites (Moeda Formation, Taquaral Valley, Minas Gerais, Brazilia). Materials Science Forum, 157-162, 1675-1680.

Schmid, S. M. and Casey, M. (1986). Complete fabric analysis of some commonly observed quartz c-axis patterns. Geophysical Monograph, 36, 263-286.

Schmid, S. M., Panozzo, R. and Bauer, S. (1987). Simple shear experiments on calcite rocks: rheology and microfabric. J. Struct. Geol., 9, 747-778.

Siegesmund, S., Helming, K. and Kruse, R. (1994). Complete texture analysis of a naturally deformed amphibolite: comparison between neutron diffraction and U-stage data. J. Struct. Geol., 16, $131-142$.

Sintubin, M. (1994). Texture types in shales and slates. In Textures of Geological Materials, edited by H. J. Bunge, S. Siegesmund, W. Skrotzki and K. Weber, pp. 221-230. Oberursel: DGM Informationsgesellschaft-Verlag.

Ullemeyer, K. (1992). Gefügeuntersuchungen an Granuliten der Südlichen Böhmischen Masse. PhD thesis (part II), University of Göttingen.

Ullemeyer, K. and Weber, K. (1994). Correction of phyllosilicate (002) X-ray pole figure measurements. In Textures of Geological Materials, edited by H. J. Bunge, S. Siegesmund, W. Skrotzki and K. Wever, pp. 83-92. Oberursel: DGM Informationsgesellschaft-Verlag.

Wassermann, G. (1939). Texturen metallischer Werkstoffe. Berlin: Springer Verlag.

Weber, K. (1981). Kinematic and metamorphic aspects of cleavage formation in very low-grade metamorphic slates. Tectonophysics, 78, 291-306.

Wenk, H.-R. and Pannetier, J. (1990). Texture development in deformed granodiorites from the Santa Rosa mylonite zone, southern California. J. Struct. Geol., 12, 177-184.

Wenk, H.-R., Bunge, H. J., Jansen, E. and Pannetier, J. (1986). Preferred orientation of plagioclaseneutron diffraction and U-stage data. Tectonophysics, 126, 271-284.

Will, G., Schäfer, W. and Merz, P. (1989). Texture analysis by neutron diffraction using a linear position sensitive detector. Textures and Microstructures, 10, 375-387. 